\title{
Relationship of Stress Coping Behaviors and Changes in Resilience during an Integrated Nursing Practicum
}

\author{
Etsuko Imoto*, Emi Yoshioka, Sayuri Kaneko \\ Faculty of Nursing, Nagano College of Nursing, Komagane, Japan \\ Email: *imoto@nagano-nurs.ac.jp
}

How to cite this paper: Imoto, E., Yoshioka, E. and Kaneko, S. (2020) Relationship of Stress Coping Behaviors and Changes in Resilience during an Integrated Nursing Practicum. Open Journal of Nursing, 10, 1026-1037.

https://doi.org/10.4236/ojn.2020.1011072

Received: October 4, 2020

Accepted: November 10, 2020

Published: November 13, 2020

Copyright $\odot 2020$ by author(s) and Scientific Research Publishing Inc. This work is licensed under the Creative Commons Attribution International License (CC BY 4.0).

http://creativecommons.org/licenses/by/4.0/

\begin{abstract}
This study aims to clarify what kinds of resilience and coping strategies students employ to successfully complete their clinical practicum and provide suggestions for instruction that will allow students to carry out effective learning activities. The study subjects were 86 students enrolled at Nursing University A for the 2019 school year and planning to take the integrated nursing practicum. The survey was conducted using an anonymous, self-administered questionnaire. The Wilcoxon signed-rank test was used to determine the amount of change in resilience factors from the surveys before and after the practicum. Subsequently, multiple regression analysis was carried out with stress coping behaviors that were significantly associated with resilience factors in univariate analysis as independent variables and the amount of change in resilience factors before and after the practicum as dependent variables. A total of 56 responses were received (response rate 65.8\%) from the 85 survey subjects. Innate resilience factors increased significantly from 41 pre-practicums to 44 post-practicums. Acquired resilience factors also increased significantly from 32 pre-practicums to 35 post-practicums ( $\mathrm{p}$ $<0.01)$. The results of multiple regression analysis found that the stress coping behavior of "changing point of view" $(\beta=0.361, p<0.01)$ and pre-practicum innate resilience factors $(\beta=-0.456, p<0.01)$ were significantly associated with innate resilience factors. Examining the relationship between the amount of change in student resilience and stress coping behaviors revealed that the stress coping behavior of "changing point of view" was associated with innate resilience. This finding suggests that resilience may be increased by changing one's perspective on an event by taking on a new way of thinking. The results suggested that helping students transform realizations made during reflection into learning and create a sense of meaning may lead to fostering innate resilience during integrated nursing practicums.
\end{abstract}




\section{Keywords}

Stress Coping Behaviors, Resilience, Integrated Nursing Practicum, Nursing Students

\section{Introduction}

Clinical practicums are often accompanied by greater psychological strain and difficulty than lectures or practice exercises in the classroom. These practicums include stressors, such as reporting to teachers or mentors and communicating with patients and their families [1]. Thus, in contrast to in-class learning activities, clinical practicums are considered an environment in which challenges are more likely to arise for nursing students (hereafter referred to as "students"). As a result, some students experience mental instability and struggle to continue their clinical practicums, while other students experience challenges but overcome them and ultimately learn a great deal.

The concept of resilience, the ability to overcome difficult situations without becoming discouraged, has been gaining attention in recent years. Resilience has been conceptualized as the ability to overcome and skillfully adapt to challenging and unexpected situations. Although resilient individuals may experience a temporary decline in health, they do not experience lasting psychological pathology [2]. As resilience derives from a variety of factors, it is a skill that anyone can possess and improve; it is a capacity for psychological recovery that anyone can learn [3]. Sumida et al. (2013) defined resilience as a latent ability in students to recover from stress that occurs during practicums [4]. In other words, it is thought that if students can manifest resilience during practicums, they will be able to recover even if they experience feelings, such as depression, and as a result will be able to retain their mental health and complete their clinical practicums. The ability to overcome and adapt to challenges, in other words, resilience, is a trait demanded by nurses [5]. Therefore, it is vital that learning support offered to students during clinical practice focuses on the human trait of overcoming difficult situations rather than the specific stresses or challenges the student is facing.

Several studies have been published on resilience during clinical practicums for nursing students. These include research on changes in resilience and its association with self-esteem before and after nursing practica [6], the association between completion of a basic nursing practicum with resilience and self-efficacy [7], changes in resilience before and after field-specific nursing practicums, and their association with difficulties and supports [8], the association between resilience and behavioral traits oriented toward problem-solving [9], the association between changes in resilience before and after psychiatric nursing practica, and stress coping behaviors [10], and differences in nursing students' resilience trait by grade level [11]. However, there have been no studies on resilience during in- 
tegrated nursing practicums, which focus on fourth-year students.

Integrated nursing practica, in which students utilize the practical nursing competencies acquired through their basic nursing education to learn the role of a nurse within an organization and make clinical judgments while multitasking to care for multiple patients as a member of a nursing team are the closest practicum to the clinical setting. Simultaneously, for students, it represents the first time they find themselves responsible for multiple patients and consider care priority levels. This differs greatly from their previous field-specific practicums and can be expected to cause stress in various ways. Understanding the coping behaviors by which students can overcome the difficulties present in the integrated nursing practicum-the final practicum of basic nursing education-will allow consideration of specific teaching strategies. Resilience can further be considered an essential topic as a means of contributing to continuing employment in the nursing profession in the future.

This study aims to clarify what kinds of resilience and coping strategies students employ to successfully complete their clinical practicum and provide suggestions for instruction that will allow students to carry out effective learning activities.

\section{Research Method}

\subsection{Survey Participants and Period}

The two-week integrated nursing practicum at Nursing University A is carried out from July to August of students' fourth year after they have completed the practicum for their specialization. The integrated nursing practicum consists of classroom lectures and clinical practicums that aim to teach students about clinical judgment, decision making, and problem-solving strategies when faced with multiple tasks. This is done by taking responsibility for multiple patients and participant observation of team leaders and team members to foster understanding of the role of the nursing profession and clinical lecture.

Study subjects were85students enrolled at Nursing University A for the 2019 school year and planned to take the integrated nursing practicum. Anonymous questionnaire surveys were administered at the orientation carried out before and after completion of the practicum. The study period was from July to August 2019.

\subsection{Survey Method}

The survey was conducted using an anonymous, self-administered questionnaire. A summary of the study was explained to students both orally and in writing following the orientation carried out before beginning the integrated nursing practicum. Questionnaires were distributed to all class members, and consent was provided by checking the "I consent" column on the questionnaire form. After all students had completed the questionnaire, the forms were placed into sealed envelopes to prevent accidental disclosure of responses and deposited 
into a collection box. Anonymous questionnaire surveys were conducted twice for comparison before and after the practicum.

\subsection{Survey Content}

The survey comprised items on 1) basic attributes, 2) resilience factors, and 3) stress coping behaviors.

1) Basic attributes

Questions included age, sex, whether the student had a part-time job, and subjective health. Subjective health was answered on a five-point scale ("good", “okay", "normal”, “not very good”, and "not good”).

2) Resilience factors

Resilience factors were measured using the Bidimensional Resilience Scale (BRS), a scale capable of measuring factors related to resilience as a human behavioral trait. The BRS was developed by Hirano (2010) and has been confirmed to be both reliable and valid [12]. The scale comprises 21 questions on a five-point scale from one ("completely disagree") to five ("completely agree"). A higher resilience factor score indicates higher resilience. BRS includes two subscales: innate and acquired factors $(\alpha=0.72$ - 0.83). Innate factors include "optimism", "control", "sociability", and "vitality"; acquired factors include "attempting to solve a problem", "self-understanding”, and "understanding others" for a bidimensional structure with a total of seven subfactors. In the context of this scale, innate resilience factors refer to resilience in which one can positively conquer a stressful or hurtful situation without being emotionally swayed by it by switching to a new goal and accomplishing it with the support of others. In contrast, acquired resilience factors refer to the ability to recover through a grasp of one's own thoughts and feelings by having the determination to consider how one would like to improve a stressful situation and reach an understanding of the situation by deepening one's understanding of oneself and others.

3) Stress coping behaviors

The Brief Scales for Coping Profile (BSCP), designed for workers, was used to evaluate stress coping behaviors. BSCP was developed by Kageyama and Kobayashi (2017) and has been confirmed to be both reliable and valid [13]. BSCP, capable of measuring stress coping behaviors, consists of six subscales: "active solution", "seeking help for solution”, “changing mood”, “emotional expression involving others", "changing point of view", and "avoidance and suppression". "Active solution" refers to striving on one's own to solve the problem. "Seeking help for solution" refers to enlisting the help of others to solve the problem. "Changing mood" refers to doing something different to alleviate one's own uncomfortable feelings, such as anxiety or irritation. "Changing point of view" refers to looking at a situation with a different perspective, way of thinking, or values to discover positives about the problem or clearly identify things that cannot be changed as pointless to think about further. "Emotional expression involving others" refers to emotionally focused coping behaviors in which one 
vents or gets someone to listen to one's uncomfortable feelings. "Avoidance and suppression" refers to suffering through or postponing, and as a result, doing nothing. The total score on the BSCP ranges from 18 to 72 points with each sub-concept having three items, which together yield from 3 to 12 points. In all cases, a higher score indicates greater use of stress coping behaviors.

\subsection{Analysis Method}

Returned questionnaire forms excluding those for which the "I consent" box was not checked or which were less than $80 \%$ complete were considered valid responses.

To begin, the Wilcoxon signed rank test was used to determine the amount of change in resilience factors from the surveys before and after the practicum. Next, using Spearman's rank correlation coefficient analysis to investigate how resilience factors and stress coping behaviors before and after the practicum were related. Subsequently, multiple regression analysis was carried out with the stress coping behaviors that were significantly associated with resilience factors as the independent variable and the amount of change in resilience factors before and after the practicum as the dependent variables. After accounting for the impact of multicollinearity, stepwise regression was used to identify independent variables capable of predicting changes in resilience before and after the practicum. Furthermore, pre-practicum resilience level was input as a predictor in multiple regression analysis, as it was thought to be correlated as a factor impacting the amount of change in resilience before and after the practicum. The normality of each distribution was verified using the Shapiro-Wilk test of normality before testing.

Statistical processing was performed using the statistical analysis package SPSS Ver. 26. The significance level was $\mathrm{p}<0.05$.

\subsection{Ethical Considerations}

To ensure that respondents could not be identified, the pre- and post-practicum survey forms were marked with matching numbers, but did not include names. Consent to the study was provided by checking the "I consent" column on the survey form. Study participation was voluntary, and it was ensured that nonparticipation or non-completion would have no impact on the class grade. The survey form followed ethical guidelines for medical research on human subjects and methods for protection of personal information. Collected data were statistically processed, stored, and securely destroyed after analysis was completed. Participants were informed that after the survey form was submitted, data could not be deleted even if they withdrew consent. Participants were also assured that information obtained from the survey would not be used for purposes outside of this research, that any findings would be published only as aggregated results, and neither the name of the nursing students nor the school would be disclosed. Lastly, participants were informed that the analysis results were intended to be 
used to benefit society through presentation at academic conferences and publications in academic journals and online.

This study was carried out after undergoing ethical review and receiving approval from the ethics committee of the Nagano College of Nursing (Approval No. 2019-6). There are no conflicts of interest to disclose.

\section{Results}

\subsection{Summary of Participants}

A total of 56 responses were received (response rate 65.8\%) from the 85 survey subjects. All 56 responses received were valid (valid response rate, 100\%).

The mean age of the participants was 21.7 years. Five subjects (8.9\%) were male and 51 (91.1\%) were female. Forty-eight students (86.7\%) were working part-time jobs. Forty-nine students $(87.5 \%)$ perceived their subjective health as "good" or "okay."

\subsection{Changes in Resilience during the Clinical Practicum}

Innate resilience factors increased significantly from 41 pre-practicums to 44 post-practicums. Acquired resilience factors also increased significantly from 32 pre-practicums to 35 post-practicums $(\mathrm{p}<0.01)($ Table 1$)$.

\subsection{Relationships between Clinical Practicum Resilience Changes and Stress Coping Behaviors}

Spearman's rank correlation coefficient was used to determine which practicum stress factors and stress coping behaviors were associated with resilience factors before and after the clinical practicum. The association with pre-practicum resilience level was also analyzed as pre-practicum resilience level was found to impact the amount of change in resilience. These analyses found that the stress coping behaviors of "active solution" $(r=0.266, p<0.05)$ and "changing point of view" ( $r=0.398, p<0.01)$ demonstrated significant relationships with the amount of change in innate resilience before and after the practicum (Table 2). Meanwhile, no significant relationships were found between stress coping behaviors and the amount of change in acquired resilience (Table 3). Next, multiple regression analysis was performed with stress coping behaviors found to have a significant relationship through Spearman's rank correlation coefficient ("active solution" and "changing point of view") and pre-practicum innate resilience

Table 1. Change in resilience scores before and after the practicum.

\begin{tabular}{cccc}
\hline & Pre-practicum & Post-practicum & \multirow{2}{*}{ P value } \\
\cline { 2 - 3 } & Median & Median & \\
\hline Innate resilience & 41 & 44 & 0.001 \\
Acquired resilience & 32 & 35 & $<0.001$ \\
\hline
\end{tabular}

Wilcoxon signed rank test. 
Table 2. Relationships between stress coping behaviors and amount of change in innate resilience before and after the practicum.

\begin{tabular}{|c|c|c|c|c|c|c|c|}
\hline & \multirow[b]{2}{*}{$\begin{array}{l}\text { Amount of } \\
\text { change in innate } \\
\text { resilience }\end{array}$} & \multicolumn{6}{|c|}{ Stress coping behaviors } \\
\hline & & $\begin{array}{l}\text { Active } \\
\text { solution }\end{array}$ & $\begin{array}{l}\text { Seeking help } \\
\text { for solution }\end{array}$ & $\begin{array}{l}\text { Changing } \\
\text { mood }\end{array}$ & $\begin{array}{c}\text { Emotional } \\
\text { expression } \\
\text { involving others }\end{array}$ & $\begin{array}{l}\text { Avoidance and } \\
\text { suppression }\end{array}$ & $\begin{array}{l}\text { Changing } \\
\text { point of view }\end{array}$ \\
\hline $\begin{array}{l}\text { Amount of change in } \\
\text { innate resilience }\end{array}$ & 1.000 & $0.266^{*}$ & 0.240 & 0.230 & 0.001 & 0.141 & $0.398^{* *}$ \\
\hline Active solution & & 1.000 & $0.276^{\star}$ & 0.006 & -0.066 & -0.169 & $0.529^{\star *}$ \\
\hline $\begin{array}{l}\text { Seeking help for } \\
\text { solution }\end{array}$ & & & 1.000 & 0.141 & 0.049 & -0.047 & $0.439^{* *}$ \\
\hline Changing mood & & & & 1.000 & 0.120 & $0.263^{*}$ & $0.352^{* *}$ \\
\hline $\begin{array}{l}\text { Emotional expression } \\
\text { involving others }\end{array}$ & & & & & 1.000 & $0.363^{* *}$ & 0.169 \\
\hline $\begin{array}{l}\text { Avoidance and } \\
\text { suppression }\end{array}$ & & & & & & 1.000 & 0.167 \\
\hline Changing point of view & & & & & & & 1.000 \\
\hline
\end{tabular}

Spearman's rank correlation coefficient ${ }^{* *} \mathrm{p}<0.01 ;{ }^{*} \mathrm{p}<0.05$.

Table 3. Relationships between stress coping behaviors and amount of change in acquired resilience before and after the practicum.

\begin{tabular}{|c|c|c|c|c|c|c|c|}
\hline & \multirow{2}{*}{$\begin{array}{l}\text { Amount of } \\
\text { change in } \\
\text { acquired } \\
\text { resilience }\end{array}$} & \multicolumn{6}{|c|}{ Stress coping behaviors } \\
\hline & & $\begin{array}{c}\text { Active } \\
\text { solution }\end{array}$ & $\begin{array}{l}\text { Seeking help } \\
\text { for solution }\end{array}$ & $\begin{array}{l}\text { Changing } \\
\text { mood }\end{array}$ & $\begin{array}{c}\text { Emotional } \\
\text { expression } \\
\text { involving others }\end{array}$ & $\begin{array}{l}\text { Avoidance and } \\
\text { suppression }\end{array}$ & $\begin{array}{l}\text { Changing } \\
\text { point of view }\end{array}$ \\
\hline $\begin{array}{l}\text { Amount of change in } \\
\text { acquired resilience }\end{array}$ & 1.000 & 0.062 & -0.019 & 0.090 & -0.170 & -0.095 & 0.076 \\
\hline Active solution & & 1.000 & $0.276^{\star}$ & 0.006 & -0.066 & -0.169 & $0.529^{\star *}$ \\
\hline $\begin{array}{l}\text { Seeking help for } \\
\text { solution }\end{array}$ & & & 1.000 & 0.141 & 0.049 & -0.047 & $0.439^{* *}$ \\
\hline Changing mood & & & & 1.000 & 0.120 & $0.263^{*}$ & $0.352^{* \star}$ \\
\hline $\begin{array}{l}\text { Emotional expression } \\
\text { involving others }\end{array}$ & & & & & 1.000 & $0.363^{* *}$ & 0.169 \\
\hline $\begin{array}{l}\text { Avoidance and } \\
\text { suppression }\end{array}$ & & & & & & 1.000 & 0.167 \\
\hline Changing point of view & & & & & & & 1.000 \\
\hline
\end{tabular}

Spearman's rank correlation coefficient ${ }^{* *} \mathrm{p}<0.01 ;{ }^{*} \mathrm{p}<0.05$.

factors as independent variables and the amount of change in innate resilience before and after the practicum as the dependent variable. These analyses found that the stress coping behavior of "changing point of view" $(\beta=0.361, p<0.01)$ and pre-practicum innate resilience factors $(\beta=-0.456, \mathrm{p}<0.01)$ were significantly associated with innate resilience factors (Table 4). 
Table 4. Relationships between stress coping behaviors and amount of change in resilience before and after the practicum.

\begin{tabular}{ccc}
\hline & \multicolumn{2}{c}{ Amount of change in innate resilience } \\
\cline { 2 - 3 } & $\beta$ & $\mathrm{p}$ \\
\hline Changing point of view & 0.537 & $<0.001$ \\
Pre-practicum innate resilience & -0.456 & 0.001 \\
Corrected R2 & & \\
$\mathrm{N}$ & & 0.554 \\
\end{tabular}

Multiple regression analysis (stepwise method).

\section{Discussion}

This study investigated how student resilience changes through an integrated nursing practicum and what kind of stress coping abilities is correlated with those changes. The results demonstrated that both nursing students' innate and acquired resilience factors significantly increased. Concerning the associations between resilience factors and stress coping behaviors, the stress coping behavior of "changing point of view" was associated with innate resilience. No stress coping behaviors were associated with acquired resilience.

\subsection{Changes in Resilience during the Clinical Practicum}

Comparison of scores before and after the practicum revealed that scores for both innate and acquired resilience factors increased significantly after the practicum.

Past research comparing changes in nursing students' resilience by grade level found that resilience was high among fourth-year students [14], and it has been suggested that practicum experience may increase resilience [6]. Similarly, this study demonstrated that resilience was higher after the integrated nursing practicum, a finding that supports past research stating that resilience is increased through practicum experience.

For students, the integrated nursing practicum consists of practicing nursing while being responsible for multiple patients as members of a team with staff members. This is the first experience that students have with clinical judgment and nursing practice while multitasking, and they are likely to experience severe stress. Sumida (2016) cites a stressful experience during a nursing practicum as a prerequisite for resilience [15]. Thus, it was suggested that the experience of overcoming a difficult situation may have impacted changes in resilience during the integrated nursing practicum, a scenario more like actual clinical practice.

\subsection{Relationships between Stress Coping Behaviors and Amount of Change in Resilience during the Clinical Practicum}

Stress coping behavior "changing point of view" was associated with the amount 
of change in innate resilience before and after the practicum. Innate resilience refers to resilience in which one can positively conquer a stressful or hurtful situation without being emotionally swayed by it by switching to a new goal and accomplishing it with the support of others [12]. This form of resilience is thought to be a trait that humans are naturally born with. Meanwhile, the stress coping behavior "changing point of view" refers to looking at a situation with a different perspective, way of thinking, or values to discover positives about the problem or clearly identify things that cannot be changed as pointless to think about further [13]. In other words, this is the act of giving positive meaning to difficult experiences in the integrated nursing practicum through support from others. Further, this means that it is possible to foster resilience by taking on a new way of thinking, rather than becoming caught up in the event. Thus, it was suggested that educational support that encourages students to change their point of view is essential.

Univariate analysis found that both "changing point of view" and "active solution" were associated with innate resilience, but "active solution" was not found to be a predictor of change in innate resilience in the results of multiple regression analysis. This is thought to be because, although the content included in "active solution" and "changing point of view" differs, the inter-item correlation was moderate $(\mathrm{r}=0.529)$. Meanwhile, stress coping behaviors were not associated with acquired resilience. In their investigation of resilience by grade level, Sugimoto, Kasahara, and Oka (2018) found that the acquired factors of "self-understanding" and "attempting to solve a problem" increased with grade level due to support and education [11]. However, the acquirable factor of "understanding others"' did not improve.

Thus, some subscales of acquired resilience increase with grade progression, but others do not change. Accordingly, it is likely that the two-week integrated nursing practicum was not long enough to see growth in acquired resilience.

\subsection{Suggestions for Instruction to Increase Resilience}

This study found a significant relationship between innate resilience and stress coping behavior from a "changing point of view." Thus, it was concluded that resilience increases when one can change one's perspective when faced with a difficult situation. This suggests that educational support enabling students to change their perspectives is essential. Innate resilience refers to resilience in which one can positively conquer a stressful or hurtful situation without being emotionally swayed by it by switching to a new goal and accomplishing it with the support of others. Since innate resilience is a trait that humans are born with, it is thought that students can recognize new perspectives on a difficult situation through support from others, such as teachers or mentors. Yamagishi, Teraoka, and Yoshitake (2010) found that feeling one had learned something from their practicum was associated with resilience [6]. Feeling that there is meaning even in difficult situations, for example, that "even though it was difficult, I learned a 
lot" gives one the strength to overcome. Furthermore, Fukushige and Morita (2013) found that self-esteem and self-efficacy were significantly higher in the high resilience group [16]. In other words, a student's ability to look forward positively, feel that they are capable, and personally experience overcoming a difficult situation may lead to cultivating resilience. Gibbs' reflective cycle is a process in which one is encouraged to notice their own tacit knowledge by explaining an event and their feelings about it and then carefully evaluating and analyzing them [17]. Drawing on this, instructors must teach students to control their emotions, overcome stress, and switch to a positive mindset. Specifically, this means turning realizations and comments conveying intentionally positive evaluations and messages into learning. It is important to create opportunities to support reflection, leading students to find meaning and change their point of view. This kind of support is likely to foster students' innate resilience.

\subsection{Limitations and Future Directions}

The results of this study are from the participants of one institution. As the curriculum for integrated nursing practicums is determined independently by each school, it is essential to reexamine the results if they are to be applied to nursing practicum in other fields or at other institutions. Therefore, it is necessary to explore other factors that modify resilience and consider what kinds of educational support are effective at fostering resilience.

\section{Conclusions}

1) Comparing resilience before and after an integrated nursing practicum revealed that both innate and acquired resilience were significantly higher after the practicum.

2) Examination of the relationship between the amount of change in student resilience and stress coping behaviors revealed that the stress coping behavior of "changing point of view" was associated with innate resilience. This finding suggests that resilience may be increased by changing one's perspective on an event by taking on a new way of thinking.

3) The results suggested that helping students transform realizations made during reflection into learning and create a sense of meaning may lead to fostering innate resilience during integrated nursing practicums.

\section{Acknowledgements}

We are extremely grateful to Nursing University A and all the students who participated in the survey.

\section{Conflicts of Interest}

The authors declare no conflicts of interest regarding the publication of this paper. 


\section{References}

[1] Kaneko, S. and Momino, K. (2015) Stress Factors and Coping Behaviors of Nursing Students during Fundamental Clinical Practice. Bulletin of Nagoya City University School of Nursing, 14, 51-57. http://id.nii.ac.jp/1124/00000997/

[2] Oshio, A., Nakaya, M. and Kaneko, H. (2002) Development and Validation of an Adolescent Resilience Scale. Japanese Journal of Counseling Science, 35, 57-65. https://www.researchgate.net/profile/Atsushi_Oshio/publication/284332745 Develo pment and validation of an adolescent resilience scale/links/57203d8908aeaced 788ad6d8.pdf

[3] Grotberg, E.H. (2003) Resilience for Today: Gaining Strength from Adversity. Prager Publishers, Westport, 4-12.

[4] Sumida, C., Hosoda, Y. and Hoshi, K. (2013) The Resilience Components of Undergraduate Nursing Students in Clinical Practicums. Journal of Japanese Society of Nursing Research, 36, 59-67. https://doi.org/10.15065/jjsnr.20130305006

[5] Taniguchi, K. and Munakata, T. (2010) The Influence of Psycho-Behavioral Factors on Nurses' Resilience: Building a Causal Model Based on Covariance Structure Analysis. The Japanese Journal of Mental Health Sociology, 16, 62-70.

[6] Yamagishi, A., Teraoka, M. and Yoshitake, Y. (2010) The Relationship between a Student's Cognition of Nursing Practice and Resilience, and Self-Esteem, Juntendo University Faculty of Health Care and Nursing. Journal of Health Care and Nursing, 6, 1-10.

[7] Murata, N., Wakeshima, R. and Furushima, T. (2012) Association between the Psychological Resilience and Clinical Training Self-Efficacy of Nursing Students after Completion of Basic Nursing Training. Medicine and Biology, 156, 47-52.

[8] Okui, R., shiramizu, M. and Mase, Y. (2014) Relationship of the Change of Resilience against Difficulties and Supports Rendered to Nursing Students during Clinical Practicum. Journal of Japan Academy of Nursing Education, 24, 67-77.

[9] Matsuo, A. and Maeda, Y. (2015) A Behavior Model for Problem Solving among Japanese Nursing Students Based on Resilience. Bulletin of Seinan Jo Gakuin University, 19, 27-36.

https://seinan-jo.repo.nii.ac.jp/?\%20action=repository action common download \&item $\mathrm{id}=49$ \&item no $=1$ \&attribute $\mathrm{id}=\% 202 \% 202 \&$ file no $=1$

[10] Ishibashi, A. (2015) Changes in Nursing Students' Resilience and Stress Coping Behaviors before and after Psychiatric Nursing Practicum. The Japanese Psychiatric Nursing Society, 58, 244-248.

[11] Sugimoto, C., Kasahara, S. and Oka, K. (2018) Grade Level Differences in Resilience of Nursing Students Measured Using Bidimensional Resilience Scale. Journal of Japan Academy of Nursing Science, 38, 18-26.

[12] Hirano, M. (2010) A Study of the Classification of Resilience Factors: Development of the Bidimensional Resilience Scale (BRS). The Japanese Journal of Personality, 19, 94-106.

[13] Kageyama, T. and Kobayashi, T. (2017) How to Confront "Stress" in a Way That Supports Mental Health. Kongo Shuppan, Tokyo.

[14] Saito, M. (2012) A Cross-Sectional Study of Resilience in Nursing Students by Grade Level: Focusing on Social Support, Self-Efficacy, and Sociality. Proceedings of the Japanese Nursing Association, 42, 7-9.

[15] Sumida, C. (2016) Concept Analysis of the Student's Resilience in Clinical Practice. Japanese Journal of Medical and Nursing Education, 25, 15-21. 
http://doi.org/10.15110/00000829

[16] Fukushige, M. and Morita, T. (2013) Factors Influencing Resilience of Nursing Students and Educational Support. Japanese Journal of Applied Psychology, 39, 19-24. https://j-aap.jp/JJAP/JAP 391 19-24.pdf

[17] Bulman, C. and Schutz, S. (2014) Reflective Practice in Nursing. 5th Edition, Wiley-Blackwell, Chichester. 